\title{
QUALITY OF BRONCHIAL ASTHMA TREATMENT- A QUESTIONNAIRE-BASED STUDY IN A TERTIARY CARE HOSPITAL IN AURANGABAD
}

\author{
Sunil Baburao Jadhav1, Philips Antony²
}

${ }_{1}^{1}$ Associate Professor, Department of Respiratory Medicine, MGM Medical College and Hospital, Aurangabad, Maharashtra, India ${ }^{2}$ Senior Resident, Department of Respiratory Medicine, Kanachur Institute of Medical Sciences, Mangalore, Karnataka, India

\begin{tabular}{l}
\hline ABSTRACT \\
\hline BACKGROUND \\
Asthma is a chronic respiratory condition characterised by airway inflammation and associated symptoms such as shortness of \\
breath and wheezing. The current level of worldwide asthma control falls far short of the goals needed for long-term management.
\end{tabular}

\section{MATERIALS AND METHODS}

The patients were subjected to chest X-ray and spirometry followed by the questionnaire developed on the basis of the GINA guidelines which consisted of 20 questions.

\section{RESULTS}

Out of 75 patients aged between $18-80$ years, majority were males. Out of them 31 (41\%) had consulted more than one doctor and $37(49 \%)$ had no knowledge about doctor's qualification. Out of the $34(45 \%)$ patients that were informed about their diagnosis, only 14 patients knew they had asthma and only 15 (20\%) patients knew the disease severity. Of the total 75 patients, 45 (60\%) were prescribed inhaled therapy with only $15(20 \%)$ patients aware of the purpose. Up to $49(65 \%)$ patients revealed that they were not given any instructions for preventive measures to lessen their symptoms. Out of 45 patients using inhalers, 32 (71\%) patients were given precautions. Only $8(11 \%)$ patients were given a plan to manage asthma in the event of a worsening condition with early signs of worsening explained to only $24(32 \%)$ patients. Only $22(29 \%)$ patients were told about the measures to be taken if symptoms increase.

\section{CONCLUSION}

For asthma education programs to be effective, the guidelines must not only reach the physicians, but also to the patients. Patient education has become accepted as an essential component in managing asthma.

\section{KEY WORDS}

Asthma, Education, Inhaler, GINA Guidelines.

HOW TO CITE THIS ARTICLE: Jadhav SB, Antony P. Quality of bronchial asthma treatment- a questionnaire-based study in a tertiary care hospital in Aurangabad. J. Evolution Med. Dent. Sci. 2018;7(46):4981-4985, DOI: 10.14260/jemds/2018/1108

\section{BACKGROUND}

Asthma is a chronic respiratory condition characterised by airway inflammation and associated symptoms such as shortness of breath and wheezing. ${ }^{1}$ Non-adherence and noncompliance to therapeutic regimens are a constant challenge to all health professionals. Epidemiological data have suggested that asthma remains poorly controlled in a significant proportion of patients ${ }^{2}$ and these data have resulted in calls for a stronger emphasis on patient-focused care in asthma. ${ }^{3}$ The Asthma Insights and Reality (AIR) surveys further gave more understanding into the actual variations in control of asthma; symptoms and the current state of asthma management with respect to the GINA guidelines. ${ }^{4}$ The AIR study found that there was significant proportion of patients continuing to have symptoms; lifestyle restrictions and require emergency care. 4

'Financial or Other Competing Interest': None.

Submission 02-08-2018, Peer Review 28-10-2018,

Acceptance 05-11-2018, Published 12-11-2018.

Corresponding Author:

Dr. Philips Antony,

Senior Resident,

Department of Respiratory Medicine,

Kanachur Institute of Medical Sciences,

Mangalore, Karnataka, India.

E-mail: phil.antony@gmail.com

DOI: $10.14260 /$ jemds/2018/1108
There is also a poor correlation between objective assessment and patients perceived severity of asthma on the basis of GINA criteria.4 The current level of worldwide asthma control falls far short of the goals needed for longterm management according to the international guidelines. In view of the rising prevalence of asthma in our society there is definitely more need for a better understanding of the asthmatic patients' perception and the treatment practice of physicians. Effective management should include positive control over asthma symptoms and acute exacerbation and improved quality of living. Hence providing right knowledge on self-monitoring, adherence of medications, good doctor patient communication and a proper patient education promotes the disease control and reduces suffering due to frequency of acute attacks. Our study therefore was aimed at exploring the quality of asthma treatment practices among adult patients in a tertiary care hospital, Aurangabad with the goal of identifying barriers to optimal management.

\section{MATERIALS AND METHODS}

It was a cross-sectional; observational study. In my study, 75 patients with bronchial asthma were studied. Information on quality of treatment of asthma was obtained from patients of Bronchial Asthma (above the age of 18 years) presenting to outpatient department for the first time by using a questionnaire (Annexure 1) developed on the basis of the GINA guidelines. ${ }^{1}$ 
The Questionnaire Contained 20 Questions which were divided into the following Four Domains-

1. Information about the health care provider (3 Questions)

2. Diagnosis and assessment of severity (4 Questions)

3. Treatment (6 Questions)

4. Patient education (7 Questions)

Many questions in this questionnaire made inferences about the doctor talking to his/her patient about the diseases, treatment, education the patient received, and whether the patient had been given information about self-management. These Questions gave insight into doctor-patient interaction, such as how doctors explain Spirometry, techniques and precautions to be taken on the use of inhalers, the purpose of each inhaler, written action plans provided to the patient and how doctors explain the early signs of worsening of asthma and its management. Subject responses were categorical (Yes/No) as well as structured multiple-choice. The percentage of subjects with different responses to each question was calculated. The sample size estimation was also done at conveniences.

\section{Sample Methodology}

Convenient sampling was done from patients with asthma attending OPD during the period of one year (2016-2017). All clinically suspected patients of bronchial asthma (the study population) on a given day were advised a chest $\mathrm{x}$-ray and spirometry for diagnostic confirmation. On follow up with said investigations, a group of asthmatics (sample) were randomly selected for the study.

\section{Study Area}

Study was conducted in a tertiary care hospital at Aurangabad in pulmonary medicine department

\section{Study Population}

All Patients aged $\geq 18$ years who presents to the OPD for the first time with history suggestive of asthma was included. They were evaluated and the diagnosis of bronchial asthma was confirmed based on the symptoms and reversible spirometry.

\section{Statistical Analysis}

Statistical analysis was done by using Microsoft Excel and statistical software.

\section{Data Collection}

Patients of bronchial asthma above the age of 18 were subjected to Chest X-ray and Spirometry after clinical evaluation. Upon diagnostic confirmation study patients were provided with the questionnaire in their language of comfort (Marathi/ Hindi/English) and were collected after completion. Collected data was compiled in MS Excel Sheet 2010. Qualitative data were represented in the form of frequencies and percentages.

\section{Annexure 1: Quality of Treatment Questionnaire}

\section{A. Information about the Health Care Provider (3 Questions)}

1. How many doctors have you consulted so far? One/two/more than $2 \ldots$
2. Where have you taken treatment from so far? Govt Hospital/Pvt. Hospital/Pvt. Clinic.

3. Do you know the specialization or qualifications of your doctor(s)? If Information available from records on his/her doctor's qualifications, please enter or otherwise, write NA (Yes/No)

\section{B. Diagnosis and Assessment of Severity (4 Questions)}

4. Has your previous doctor told you what are you suffering from? If yes, please specify the name of the disease (Yes/No).

5. Has your previous doctor told you about the severity of your disease? (Yes/No)

6. Have you ever taken a lung function test (Spirometry: physician to explain briefly) If yes, how many times so far? (Yes/No)

7. Has your doctor assessed your disease with a peak flow meter (show the PEF meter) (Yes/No)

\section{Treatment (6 Questions)}

8. Has your doctor prescribed any inhalation device? Which one? Yes/No

(If no, go to Question no. 16)

9. If yes, how many types of inhalation medicines are you taking?

10. If more than one, has your doctor told you about the purpose of each inhalation drug and when each has to be taken? (Yes/No/NA)

11. How did you learn the use of inhalers? From the doctor/package insert/other clinic staff/another patient/others.

12. Has your doctor advised you on any precautions while using inhalers? (Yes/No)

13. For how many years have you been using the inhalers?

\section{Patient Education (7 Questions)}

14. Has your doctor given you a written plan to manage your disease (other than the prescription)?(Yes/No)

15. Has your doctor told you what the early signs of worsening of asthma are? (Yes/No)

16. Has your doctor told you what to do if symptoms increase at any time? (Yes/No)

17. Has your doctor advised you to use a peak flow meter at home (show the PEF meter)? (Yes/No)

18. Has your doctor told you about any preventive measures, other than the use of drugs, to lessen your symptoms? (Yes/No)

19. Has your doctor told you how long treatment will continue? (Yes/No)

20. Has your doctor provided you any educational material about your disease? (Yes/No)

\section{RESULTS}

\section{Age Wise Distribution}

In my study, 75 patients with bronchial asthma were studied. Age wise distribution of the patients enrolled in the study is shown in Figure 1. Majority of the patients presented in the age group 21-30 years which was followed by the age group 31-40 years. 


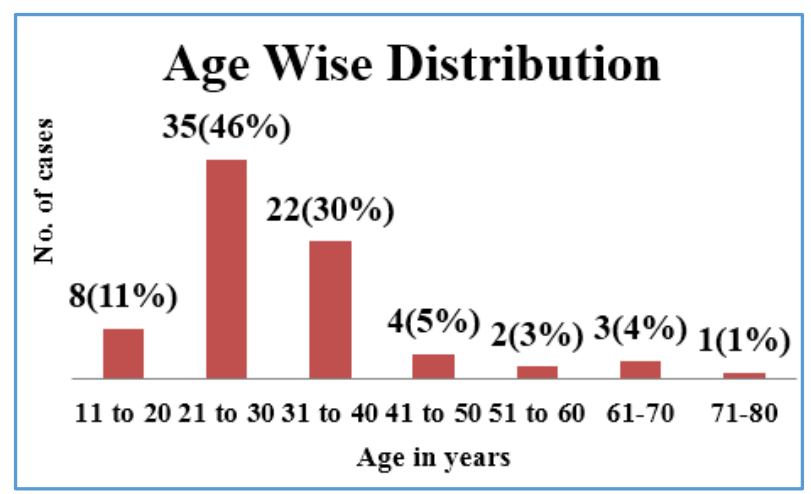

\section{Sex Wise Distribution}

In my study, out of 75 cases studied, majority of patients were males (46 patients) and females were 29 cases. The results are shown in Table 1.

\begin{tabular}{|c|c|c|}
\hline Sex & No. of Cases & \% of Cases \\
\hline Male & 46 & 62 \\
\hline Female & 29 & 38 \\
\hline \multicolumn{2}{|c|}{ Table 1. Sex Wise Distribution } \\
\hline
\end{tabular}

Figure 1. Age Wise Distribution

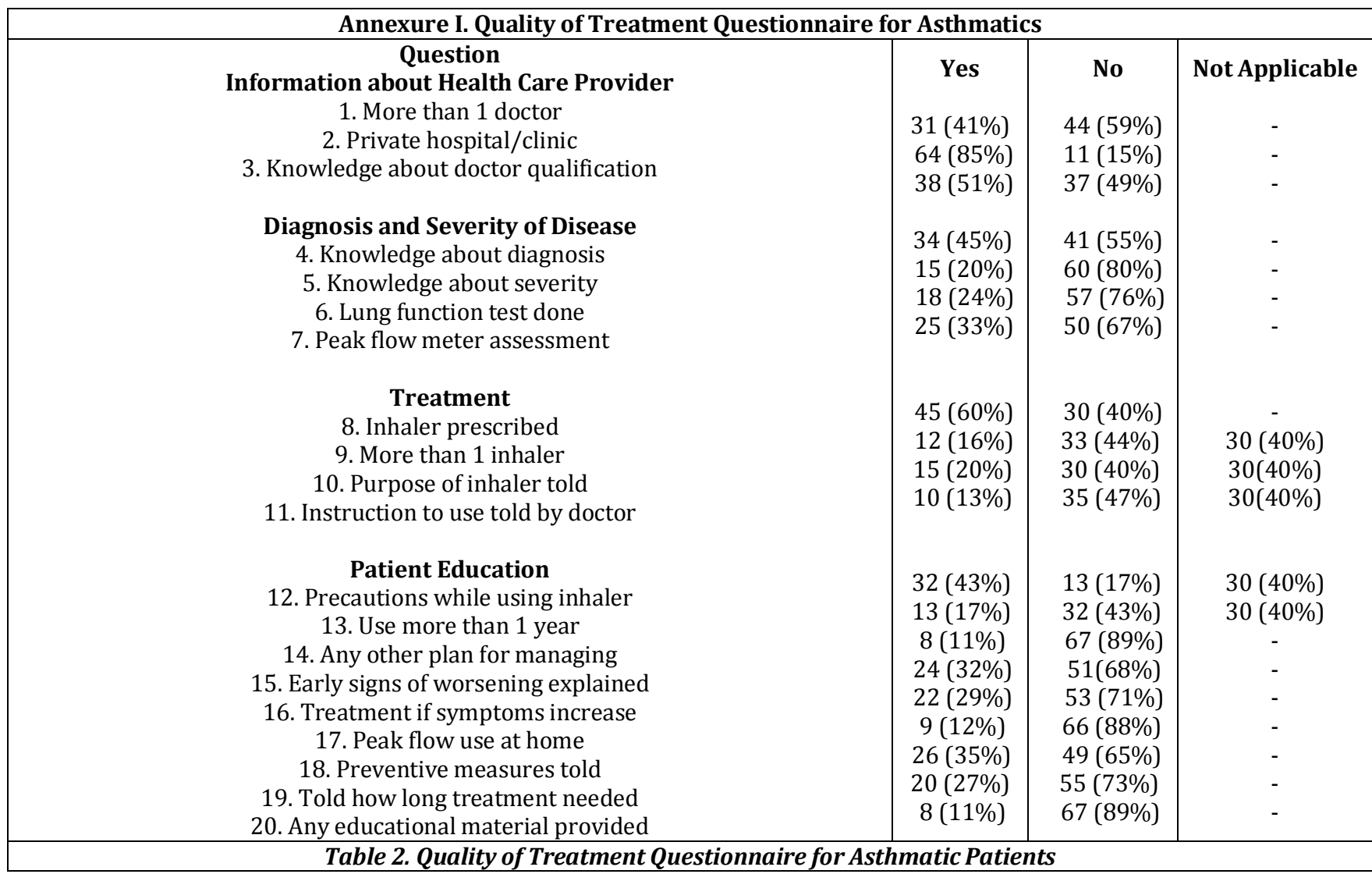

\section{Information about Health Care Providers}

Of the 75 patients, $31(41 \%)$ had consulted more than one doctor before visiting the referral chest clinic. Up to 37(49\%) patients had no knowledge about their doctor's qualification. Among 38 (51\%) patients who knew the qualifications of their doctor, 20 (53\%) patients consulted MBBS doctors, 8 (21\%) went to doctors with MD degree and 10 (26\%) consulted practitioners from the alternative systems of medicine (Homeopathy, Ayurveda etc.).

\section{Diagnosis and Assessment of Severity}

Out of the $34(45 \%)$ patients that were informed by their doctors the diagnosis of their disease but only 14 patients were informed that they were suffering from asthma. Only $15(20 \%)$ patients were told about the severity of their disease. Lung function test and peak flow measurement were done in only $18(24 \%)$ and $25(33 \%)$ of patients, respectively.

\section{Treatment}

Of the total 75 patients, $45(60 \%)$ were prescribed inhaled therapy by their doctors. Of these 45 patients, 12(27\%) patients were using more than one inhaler and only 15(20\%) patients were aware of the purpose of inhalation. 35(47\%) patients revealed that they learnt the use of inhalers from the package insert, or hospital staff and only 10 (13\%) patients learnt it from their doctor.

\section{Patient Education}

Up to 49 (65\%) of patients revealed that they were not given any instructions regarding the preventive measures to lessen the symptoms of asthma, 55 (73\%) patients was not told how long they would have to continue treatment and up to 67 (89\%) patients were not provided with any educational material. Out of 45 patients using inhalers, 32 (71\%) patients were given precautions while using inhalers and $13(17 \%)$ patients were using the inhalers for more than one year. Only $8(11 \%)$ patients were given a plan to manage asthma in the event of a worsening condition. Early signs of worsening of the condition were explained to only $24(32 \%)$ patients. Only $22(29 \%)$ patients were told about the measures to be taken if asthma symptoms increase. Nine (12\%) patients were advised to use peak flow meter at home. 


\section{DISCUSSION}

In our study of 75 asthmatic patients, age group ranged between 18-72 years of age, the most affected age group was seen to be between 18-40 years. In a study done by Bartosz et $a l, 5$ the age group showed a wide variation ranging from 18-84 years. Majority of our patients (62\%) were males and this pattern of sex prediction for asthma was seen in a recent report of ICMR ${ }^{6}$, where nearly 7 million sufferers were males and just over 6 million were women and also in this study the worst affected age group was 15-35 years which was also seen in our study.

1. Information about Health Care Providers: In our study, $41 \%$ of the patients had consulted more than one doctor before visiting the referral chest clinic, 51\% had knowledge regarding the doctor's qualification. Among doctors, 53\% were MBBS doctors, $21 \%$ with MD degree and $26 \%$ had consulted practitioners with other qualifications. In the study conducted by Anita et al, ${ }^{7}$ $66 \%$ of the patients had consulted more than one doctor, $56 \%$ had knowledge regarding the qualification of the doctor, and among the doctors, $24 \%$ were MBBS doctors, $20 \%$ with MD degree and $12 \%$ were with alternative qualifications.

2. Diagnosis and Assessment of Severity: In our study it was found that lung function test and peak expiratory flow measurement (PEFR) was done only in 24\% and $33 \%$ patients respectively. In a study conducted by A A Raheem et al $^{8}$ to analyze doctor's knowledge on peak flow meter use, around $70.3 \%$ of the doctors considered that peak flow meter is useful in making a diagnosis while $78 \%$ would use it in assessing the severity of asthma; but only $16.7 \%$ and $20.7 \%$ reported regular use of PEFR for the diagnosis and severity assessment of asthma. This shows that there is a high degree of underutilisation and inadequate knowledge of the use of PEFR/spirometry and in order to provide effective patient treatment and management, accurate classification of asthma severity is needed, and this can be done by the use of spirometry/PEFR meter.

In our study only 14 patients were correctly informed that they were suffering from asthma. This finding is consistent with an earlier study from Australia which reported that most practitioners believed that informing a patient that he or she has asthma is not important. ${ }^{9}$ Both under-diagnosis and under-assessment of asthma severity may lead to under-treatment and potentially avoidable morbidity. Diagnosis of asthma and assessment of asthma severity is based not only on careful history taking and clinical examination, but also on objective measures of airway obstruction and airway hyper-responsiveness, and also atopy. This might need investigation of spirometry which should be performed in all patients where asthma is being considered as a possible diagnosis and regular PEFR should be done to try and establish the evidence of PEFR variability as a marker of asthma.

3. Treatment: In our study, 45 patients were prescribed inhaled therapy, out of which 12 were using more than one inhaler. But only 15 patients knew the purpose of the inhaler prescribed and merely 10 patients were instructed how to use by the doctors and the rest 35 patients learnt the instructions either from package insert or from hospital staff. This was in concordance with a study done by Gupta Vitull et al ${ }^{10}$ in which only $6.2 \%$ patients were instructed how to use the inhaler by doctors and was in discordance with a study done by Melani S et al ${ }^{11}$ in which $58 \%$ of the patients were instructed by the doctor. Patient education is very important in proper use of delivery devices and effectiveness of aerosol therapy. Whatever be the chosen inhaler, education from health caregivers plays a major role in improving inhaler technique and compliance.

4. Patient Education: In our study out of 75 asthmatic patients, only $11 \%$ patients were provided with an action plan. This was in concordance with a study done by Forero et $\mathrm{al}^{12}$, in which only $9 \%$ of patient with asthma had an action plan. Education directed toward asthma self-management emphasizes patient participation in symptom monitoring and control.

According to the study done by Gibson et al, ${ }^{13}$ patients who practices self-monitoring along with the use of a written action plan and regular medical review have shown to undergo significantly fewer hospitalizations, emergency department visits, and loss of time from work.

In our study only 9 patients were advised the use of peak flow meter at home. A research study which was done by Bheekie et al 14 to compare the use of patientperformed peak flow meter and symptom monitoring as asthma self-management tools showed that PEFR selfmonitoring is a more useful asthma tool than symptom self-monitoring.

\section{CONCLUSION}

Patient education has become accepted as an essential component in managing asthma. Asthma education involves providing information that will allow patients to understand their disease, to have an effective action plan when faced with worsening of asthma and to eliminate environmental triggers. For asthma education programs to be effective, the guidelines must not only reach physicians and but also to the patients. Thus far, the treatment guidelines have fallen short of being adequately taken up by the physicians and thus face problems in disseminating information to the patients. Patients with asthma lacked understanding of the function and the use of asthma medications and of techniques in managing exacerbations. These findings are discouraging because proper asthma education can substantially improve their understanding of the disease and of pulmonary function tests, symptoms and of appropriate use of medications.

\section{REFERENCES}

[1] Global Initiative for Asthma (GINA). Global Strategy for Asthma Management and Prevention 2015. http://www.ginasthma.org/local/uploads/files/GIN A_Report_2015_Aug11.pdf.

[2] Price D, Fletcher M, van der Molen T. Asthma control and management in 8, 000 European patients: the REcognise Asthma and Link to Symptoms and Experience (REALISE) survey. NPJ Prim Care Respir Med 2014;24:14009. 
[3] Canonica GW, Baena-Cagnani CE, Blaiss MS, et al Unmet needs in asthma: Global Asthma Physician and Patient (GAPP) Survey: global adult findings. Allergy 2007;62(6):668-74.

[4] Rabe KF, Adachi M, Lai CK, et al. Worldwide severity and control of asthma in children and adults: the global asthma insights and reality surveys. J Allergy Clin Immunol 2004;114(1):40-7.

[5] Uchmanowicz B, Panaszek B, Uchmanowicz I, et al. Clinical factors affecting quality of life of patients with asthma. Patient Prefer Adherence 2016;10:579-89.

[6] Taylor L. India's asthma market "to grow $10 \%$ a year". Pharma times (Online) 2010. www.pharmatimes.com/article/10-12-08/

[7] Kotwani A, Chhabra SK, Tayal V, et al. Quality of asthma management in an urban community in Delhi, India. Indian J Med Res 2012;135(2):184-92.

[8] Raheem AA, Soremekun RO, Adeniyi OF. Knowledge, awareness and practice of the use of peak flow meters by physicians in the management of asthma in children. African Journal of Respiratory Medicine 2014;9(1):28-32.

[9] Coates JR, Steven ID, Beilby J, et al. Knowledge of and reported asthma management among South Australian general practitioners. Br J Gen Pract 1994;44(380):123-6.
[10] Vitull G, Sonia G, Yashpal J, et al. To study the type of inhaler devices used and errors in inhaler technique committed by patients of chronic pulmonary diseases in Punjab. http://www.japi.org/march_2009/respiratory_poster _sessions.html.

[11] Melani AS, Zanchetta D, Barbato N, et al. Inhalation technique and variables associated with misuse of conventional metered-dose inhalers and newer dry powder inhalers in experienced adults. Ann Allergy Asthma Immunol 2004;93(5):439-46.

[12] Forero R, Bauman, Young L, et al. Asthma prevalence and management in Australian adolescents: results from three community surveys. Journal of Adolescent Health 1992;13(8):707-12.

[13] Gibson PG. Monitoring the patient with asthma: an evidence-based approach. J Allergy Clin Immunol 2000;106(1 Pt 1):17-26.

[14] Bheekie A, Syce JA, Weinberg EG. Peak expiratory flow rate and symptom self-monitoring of asthma initiated from community pharmacies. J Clin Pharm Ther 2001;26(4):287-96. 